\title{
From Neurons to Social Beings: Short Review of the Mirror Neuron System Research and Its Socio-Psychological and Psychiatric Implications
}

\author{
Hyeonjin Jeon ${ }^{1}$, Seung-Hwan Lee ${ }^{1,2}$ \\ ${ }^{1}$ Clinical Emotion and Cognition Research Laboratory, ${ }^{2}$ Department of Psychiatry, Inje University Ilsan Paik Hospital, Goyang, Korea
}

\begin{abstract}
The mirror neuron system (MNS) is a brain network activated when we move our body parts and when we observe the actions of other agent. Since the mirror neuron's discovery in research on monkeys, several studies have examined its network and properties in both animals and humans. This review discusses MNS studies of animals and human MNS studies related to high-order social cognitions such as emotion and empathy, as well as relations between MNS dysfunction and mental disorders. Finally, these evidences are understood from an evolutionary perspective.
\end{abstract}

KEY WORDS: Mirror neurons; Social cognition; Mental disorders.

\section{INTRODUCTION}

The mirror neuron system (MNS) is a network of neuron groups that discharge when an individual performs an action and/or observes an action of another agent. The MNS is divided into two principal hubs; the premotor area in the frontal lobe and the inferior parietal lobule (IPL). ${ }^{1,2)}$ Additionally, the superior temporal sulcus (STS) is considered to be a key area of the MNS." Mirror neurons were first discovered in area F5 of the ventral premotor cortex (PMv) in macaques. ${ }^{4-6)}$ They fire when monkeys observe other individuals grasp toward objects and when the monkeys execute the grasping motion themselves. Some neurons in the F5 posterior (F5p) area that respond to the presentation of objects as the monkey grasps an object are called "canonical neurons." ${ }^{\text {",8) }}$ The F5p is also known as a hand-related area that encodes goal-directed actions. Both motor and mirror neurons are located in the F5 convexity (F5c) area and they fire during both observation and execution of specific goal-directed actions involving

Received: July 24, 2017 / Revised: November 22, 2017

Accepted: December 14, 2017

Address for correspondence: Seung-Hwan Lee, MD, PhD

Department of Psychiatry, Inje University Ilsan Paik Hospital, 170

Juhwa-ro, Ilsanseo-gu, Goyang 10380, Korea

Tel: +82-31-910-7260, Fax: +82-31-910-7268

E-mail: Ishpss@hanmail.net the hand and mouth. ${ }^{9)}$

In macaques, the frontal mirror area of the brain is divided into the lateral surface area 4 (primary motor cortex; $M 1$ ), caudal part of area 6 (also a part of M1), medial surface area 6 (supplementary motor area; SMA) and premotor area. The premotor area is divided into caudal part (PMc) - with a direct connection to subcortical areasand rostral part (PMr) that indirectly affects motor generation. The F5 area is a part of the parietal-frontal and prefrontal-frontal networks. ${ }^{10)}$ Kraskov et al. ${ }^{11)}$ have revealed that pyramidal tract neurons (PTN) in F5 suppress firing during observation but activate firing during movement. They interpreted the results as an inhibition effect suppressing motor generation during observation. Contrastingly, Vigneswaran et al. ${ }^{12)}$ found that some PTN fired more during action observation when they recorded a signal from PTN in the area F1. Early mirror neuron studies suggested that mirror neurons are only engaged in action execution and in understanding the intention and transformation of visual perception into action execution. They suggest that the PMv has a connection with the caudal part of the inferior frontal gyrus (IFG). The IFG is also known as Broca's area, a special motor area for human language generation. ${ }^{13,14)}$

Mirror aspects were also discovered in the IPL of macaque brains. ${ }^{15)}$ Mirror neurons in the parietal area PF/PFG of the

(c) This is an Open-Access article distributed under the terms of the Creative Commons Attribution Non-Commercial License (http://creativecommons.org/licenses/by-nc/4.0) which permits unrestricted non-commercial use, distribution, and reproduction in any medium, provided the original work is properly cited. 
IPL also discharge during both the observation and execution of complex actions such as grasping an object to place it at a target locus or to eat it. Moreover, activity is modulated by the final goal of the action. ${ }^{16)}$ The IPL receives visual information from eyes and somatosensory information from mouth, hands, and arms. ${ }^{17)}$ This suggests that the visuo-motor organization of the IPL may build the neural basis of the ability to understand the intention of others' action. ${ }^{18)}$

Research shows that the STS also has a mirror property. The STS is a brain area which responds to biological motions. ${ }^{19-21)}$ It is not generally considered a part of the MNS because it does not have motor properties. ${ }^{2)}$ The STS provides an audiovisual-to-motor link, that is, integration between seeing, hearing, and doing. ${ }^{22)}$ Via the IPL, the area F5 is connected to higher-order visual areas of the STS. ${ }^{2)}$ The first stream originates from a sector in the upper bank of the STS (STPm), reaches the parietal area PFG, and terminates in the area F5c. The second stream arises in the lower bank of the STS, reaches the anterior intraparietal area (AIP), and then the area F5a. ${ }^{23,24)}$ Thus, recent literature suggests that the STS be considered a part of temporo-parieto-premotor pathways and the MNS. ${ }^{25,26)}$

Experiments comparing execution, imitation, observation, and imagination conditions using various neuroimaging techniques has revealed a network of the MNS. ${ }^{26-29)}$ We present key regions and subregions of the human MNS in Figure 1. The key areas consist of the SMA, IPL, and STS. Subregions in the frontal lobe are the dorsal and PMv, IFG (including Broca's area), and M1, which are re- lated to motor function. The subregions in the parietal lobe include the primary somatosensory cortex (S1). The temporal and occipital subregions include the posterior middle temporal gyrus (pMTG) and middle temporal (MT/V5) area. Interestingly, the fusiform face area (FFA) is related with specific conditions such as facial expressions. ${ }^{30,31)}$

In this review, we first introduce various properties of mirror neurons based on animal electrophysiology. We then discuss the relationship between human MNS and higher-order cognitive abilities such as empathy and social cognition and conclude with an exploration of clinical connotations related to MNS dysfunction and mental disorders.

\section{MIRROR NEURON SYSTEM RESEARCH}

\section{MNS Research in Animals}

Multiple properties of mirror neurons from primate studies

Multiple properties of mirror neurons have been revealed in studies on primates' premotor mirror neuron. Rizzolatti et al. ${ }^{32)}$ reported that some F5 neurons fire during grasping, but not holding, while others fire during holding, but not grasping. Umiltà et al. ${ }^{33)}$ showed that more than half of the F5 mirror neurons discharged even in the invisible motor-action condition. Some neurons respond to observations of goal-directed actions (experimenter's hand or mouth actions related to food items) but

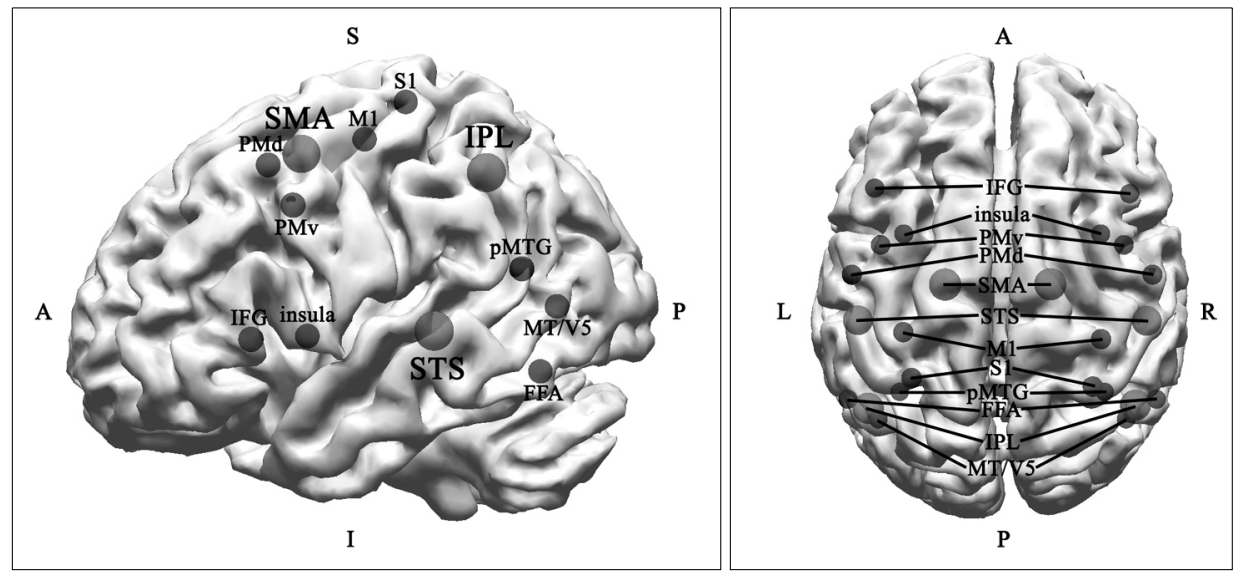

Fig. 1. Key regions (red, large sphere) and subregions (blue, small sphere) of the mirror neuron system. The image on the left is lateral view of left hemisphere and that on the right is top view of both hemispheres.

S, superior; I, inferior; A, anterior; P, posterior; IFG, inferior frontal gyrus; PMv, ventral premotor area; PMd, dorsal premotor area; SMA, supplementary motor area; STS; superior temporal sulcus; M1, primary motor cortex; S1, primary somatosensory cortex; pMTG, posterior middle temporal gyrus; FFA, fusiform face area; IPL, inferior parietal lobule; MT/V5, middle temporal area. 
not to observation of the object alone or mimicking of action without the object. ${ }^{4,5)}$ Some mirror neurons fire when macaques break a peanut and when they observe someone else breaking a peanut, as well as when the macaques hear the sound of a peanut breaking. ${ }^{10,34)}$ These were named audio-visual mirror neurons. ${ }^{23)}$ These data show that intentions of the actions of others can be recognized by the mirror mechanism. Thus, it strongly suggests that macaques can "read minds." ${ }^{35)}$ Later, Ishida et al. ${ }^{36)}$ found visuo-tactile bimodal mirror neurons in the ventral intraparietal area of macaque brains, implying that there are not only multimodal properties in the MNS, but also bodily-action representations of self and others.

Mirror neurons may be located on the summit of the where/how visual pathway. The responses of some premotor mirror neurons were significantly modulated when the observed actions were executed in macaques' peripersonal space, while the remaining neurons discharged more vigorously when the observed actions were executed in macaques' extrapersonal space. ${ }^{37)}$ These mirror neurons encode the spatial position of an observed action. More interestingly, Caggiano et al. ${ }^{38)}$ reported that some of premotor mirror neurons seem to visually encode actions in a view-dependent manner (frontal vs. side view). In their study, the visual responses of mirror neurons were studied by presenting the same actions as seen from different points of view, including also the actor's point of view. The discharges of mirror neurons were modulated not only by the action being observed, but also by the perspective from which it was observed.

Studies have recently examined the social implications of the MNS such as emotion and facial gestures in macaques. Ferrari et al. ${ }^{39)}$ found evidence supporting that facial-imitation capabilities during the first week of life predicts the development of voluntary motor skills during the first year of life in macaques. This suggests that imitation abilities reflect not only general motor functions during development but also mirror neuron activity.

\section{MNS of non-primate vertebrates}

Songbirds have an auditory-vocal MNS involved in singing and learning of new songs. Their song system is commonly divided into two functionally distinct pathways; the posterior descending pathway (PDP), necessary for both the acquisition of new songs and production of learned song, and the anterior forebrain pathway (AFP), necessary only for acquisition. ${ }^{40,41)}$ HVC (high vocal center with a former terminology), is a telencephalic nuclei, where auditory and vocal motor information emerge. ${ }^{42)}$ Although it has been revealed that the HVC is not the highest order song related nuclei, it is the origin in which projection to the song-motor pathway (SMP) and AFP begins. ${ }^{43)}$ In mammalian terms, HVC of songbirds is similar to the Broca's area, PDP can be regarded as a homolog of a motor pathway which descends from the cerebral cortex to the brainstem, whereas the AFP can be considered as cortical-basal ganglia loop and thalamus involved in working memory. ${ }^{40,41,44-48)}$ The HVC contains two types of neurons; $H_{V} C_{R A}$ neurons which innervates the song motor nucleus RA (robust nucleus of the arcopallium) for singing pre-learned songs and $\mathrm{HVC}_{\mathrm{X}}$ neurons which provides an input to a striatopallidal structure area $X$ (avian medial striatum) in the AFP for acquisition of a new song or arrangement of a pre-learned song. ${ }^{42,43,45)}$

Similar to Broca's aphasia, adult songbirds with HVC lesions lose their singing ability, although they continue to produce innate vocalizations such as alarm calls and simpler vocalizations that resemble the babbling vocalizations produced by juvenile songbirds at the earliest stages of song learning. ${ }^{44,49)}$ Interestingly, songbirds with HVC lesions also show deficits in the ability to recognize the songs of other birds of their own species, ${ }^{50)}$ or to learn new contingencies to these songs. ${ }^{51)}$ These results suggest that the HVC serves as auditory premotor and mirror neurons. ${ }^{41)}$

Researchers argue that dolphins may also have the MNS. Bottlenose dolphins can use parts of their bodies and comprehend gestural symbols, suggesting that they understand a mirror image and have self-recognition. ${ }^{52-54)}$ Their mirroring system supports social intelligence, such as imitating other dolphins and humans. ${ }^{55)}$ As Jeannerod notes that self-recognition is a prerequisite for establishing social communication with others, ${ }^{56)}$ it is sufficient to say that dolphins may have the MNS.

Von Economo neurons (VENs) have been proposed as neurohistological evidence of higher cognitive abilities such as social and emotional cognition, awareness, and intuition and have been described in humans, great apes, elephants, cetaceans. ${ }^{52,57-60)}$ The VENs are spindle-shaped, large bipolar projection neurons located in layer 3 and 5 of the anterior cingulate cortex (ACC), anterior insular (AI), and frontopolar (FP) cortex. Considering dolphins' 
social intelligence and the existence of VENs, the supposition that dolphins may have the MNS is justified.

\section{Expansion of MNS Research in Humans}

Neural correlates of MNS activity in humans

Electroencephalography (EEG) methods have mainly focused on mu rhythms. Mu rhythms refer to sensorimotor activity in alpha bands (8-13 Hz in adults, $6-9 \mathrm{~Hz}$ in children) recorded over central scalp locations $\mathrm{C} 3, \mathrm{Cz}$, and C4; it is also referred to as "rolandic alpha." ${ }^{2,61)} \mathrm{Mu}$ power decreases during both execution and observation of movements, and even when imagining movements. ${ }^{22,62)}$ It is therefore called mu suppression or mu power desynchronization. Some studies have reported infant's mu rhythm in central regions of the brain. ${ }^{61,63)}$ A recent EEG study indicated greater mu suppression (putatively reflecting mirror neuron activation) in infants and adults when observing transitive movements compared to intransitive movements. ${ }^{64)}$

Hari et al.'s source localization study ${ }^{65)}$ of mu rhythm activity based on magnetoencephalography (MEG) identified sensorimotor regions. Concurrent functional magnetic resonance imaging ( $\mathrm{fMRI}$ ) studies suggest that $\mathrm{mu}$ suppression may represent activity in brain areas of the MNS. ${ }^{66-69)}$ On the other hand, some researchers suggest that mu suppression is not a perfect index of MNS activity. Aleksandrov and Tugin ${ }^{70)}$ compared mu suppression from various types of motor activity and found that mu suppression was not significantly lower than it was in conditions where participants viewed human movement. They argued that mu suppression instead depends on the attention demands of the task, which decreases over time. Perry and Bentin ${ }^{71)}$ found a similar pattern of changes in EEG power at the occipital and central electrodes. They argued that the significant differences could be attributed to differences in attentional demands between conditions, rather than differences in mirror neuron activity.

Studies using EEG and EMG have also included betaand theta-frequency band activity. Beta band is usually defined as 13 to $35 \mathrm{~Hz}$, with a typical peak frequency of $\sim 20 \mathrm{~Hz}$. Researchers have also suggested that changes in beta activity index mirror neuron activity. ${ }^{72-74)}$ Beta suppression is more related to motor processing and the primary motor cortex, while mu rhythm is linked predominantly to the somatosensory system. ${ }^{75,76)}$ Theta rhythm $(4-8 \mathrm{~Hz})$ is also related to movement and activity in non-mu rhythm frequency bands by voluntary movement from the somatosensory area have been considered as an alternative index of the MNS function. ${ }^{77,78)}$

A number of transcranial magnetic stimulation (TMS) studies provide another putative measure of the human MNS. For example, Heiser et al. ${ }^{79)}$ stimulated the Broca's area with repetitive TMS (rTMS) while participants perform a key-press experiment. In their study, participants imitated a key-pressing movement done by another individual in experimental condition. In the control condition, participants pressed the keys in response to a red dot indicating the key to be pressed. rTMS lowered the participants' performance during imitation but not during the control task. That is, a transient lesion by rTMS over left or right IFG induced a selective impairment of action imitation.

fMRI has been a popular research method in MNS studies. lacoboni et al. ${ }^{80)}$ conducted the first fMRI study with imitation. Participants were asked to observe, execute, or imitate the hands action on the screen. The IFG pars opercularis (IFGpo), posterior parietal cortex, and parietal operculum showed higher activation during imitation than during execution, and the former two areas were activated during observation but less than they were during execution. Buccino et al.'s fMRI study ${ }^{81)}$ found bilateral premotor and parietal activations during object-related movements, and only premotor activation during non-object-related movements.

Lui et al. ${ }^{82)}$ reported activations in key regions of the MNS when human participants observed mimed and meaningless movements. In addition, fMRI studies have consistently shown activation of MNS areas when participants perform, observe, and imagine a movement; when participants look at point-light biological animations or non-biological motions likely to evoke associations with biological action; and when participants hear object-directed action sounds. ${ }^{2,83-86)}$ Caspers et al.'s meta-analysis ${ }^{28)}$ on human MNS studies with $\mathrm{FMRI}$ and positron emission tomography confirmed basic key regions such as SMA, IPL, and STS activation in observation, imitation, and execution conditions and presented multiple associative areas. Molenberghs et al. ${ }^{87)}$ also conducted a similar meta-analysis study on human MNS and consolidated MNS regions.

Emotion, empathy, theory-of-mind, and MNS

Some researchers argue that the MNS is engaged during the experience of emotion. For example, disgust induced 
by unpleasant odor increase activity level of the anterior insular, and the insula is also activated by the observation of disgust in others. These data strongly suggest that the insula contains neural populations that are activated both, when participants experience disgust and when they see it in others. ${ }^{88,89)}$ Disgust is a very basic emotion whose expression has an important survival value for the conspecifics. Thus, the insula is the primary cortical area not only for chemical exteroception, such as gustation and olfaction, but also for the interoceptive state of the body. A mirror mechanism is also present in the insula and rostral cingulate cortex (rACC). ${ }^{90,91)}$ This emotional mirroring system gives the observer a direct feeling of what others feel. The functional connection between the motor/premotor regions and insula limbic system is considered as a core neural system for emotion processing. ${ }^{88,92)}$

The posterior sector of the insula is characterized by connections among auditory, somatosensory, and premotor areas. From these data, it is clear that the insula is not exclusively a sensory area. In particular, emotional reactions to pain investigated using an fMRI paradigm showed that the same sites of the anterior insula and cingulate cortex were active in both conditions: when participants received an electric stimulation to induce pain and when participants observed their partner receiving a painful stimulation. ${ }^{90,93)}$ The mirroring mechanism in empathic pain is similar to mechanism in empathic disgust.

Molnar-Szakacs ${ }^{94)}$ suggested that perception of actions extends empathy and even morality through MNS. Moll et al. ${ }^{95)}$ revealed that STS was more activated when participants saw pictures conveying moral violations than pictures that were emotionally unpleasant but without moral connotations. The results suggest that a network consisted of core regions of MNS, including the orbitofrontal cortex (OFC), medial frontal gyrus (MFG) and STS, is engaged in social cognition such as moral processing.

The idea that motor system may support social cognition and behavior has been adopted in MNS studies. ${ }^{96)}$ Theory-of-mind (ToM) refers to the metacognitive ability to infer another person's mental state, including their beliefs and desires, from their experiences and behavior. ${ }^{97}$ Empathy-related processing of emotional facial expressions recruits brain areas involved in mirror neuron and ToM mechanisms. Thus, once actions of another individual are represented and understood in terms of one's own actions, it is possible to predict the mental state of the observed individual, leading to a ToM. ${ }^{22,98,99)}$ The neural network supporting cognitive aspects of ToM includes temporo-parietal areas, the medial prefrontal cortex (mPFC), and temporal poles. ${ }^{35,100,101)}$ The brain regions supporting ToM and structures previously associated with the human MNS are activated during the attribution of emotion to oneself and the other person. The activation of mirror neurons in a task relying on empathic abilities without explicit task-related motor components supports the view that mirror neurons are not only involved in motor cognition, but also in emotional interpersonal cognition. ${ }^{102)}$ Gallese ${ }^{103,104)}$ proposed the "shared manifold hypothesis" that people recognize other human beings as similar to us, suggesting that people can "read minds." This hypothesis is associated with the argument that people perceive emotion in others by activating the same emotion in themselves. ${ }^{91,92,105-109)}$

\section{Social action and MNS}

Oberman et al. ${ }^{98)}$ measured EEG when participants were watching a social interaction video clip. The MNS is less responsive to out-groups and most responsive to ingroups, and therefore holds implications for empathy and prejudice. ${ }^{110,111)} \mathrm{A}$ recent study investigated whether the MNS is more closely related to a type- 1 (automatic, reflexive mental process) or type- 2 process (deliberate decision-making and inferring of internal states). ChristovMoore and lacoboni ${ }^{112)}$ compared brain activations when participants imitated facial expression after pain observation and engaging in a dictator game. Activation levels in the pain observation situation predicted an altruistic decision in dictator game and a positive correlation was found in the superior parietal lobe, the pain-processing area. A network comprising cortical midline structures (CMS), including the mPFC, ACC, and precuneus, has been associated with self-processing and social cognition. ${ }^{113,114)}$ As the MNS and CMS both seem to be involved in self/other representations, the direct connections between the precuneus - a major node of the CMS and the $\mathrm{IPL}$ - and the posterior component of the MNS can be an evidence of the interaction between two systems. ${ }^{27,115)}$ Lou et al. ${ }^{116)}$ suggest that this is one possible pathway in which such interactions might occur. The CMS shares a part of neural structures with the default mode network (DMN) that is generally active under the resting state. Thus, future studies on the association between these two 
networks can help understand the link between human cerebral processes and social abilities.

\section{Clinical implications of MNS research}

A reduction in mirror neuron activity may be involved in the pathophysiology of psychiatric conditions that are characterized by social cognitive deficits. Prime examples are autism, schizophrenia, and psychopathy. ${ }^{98,117-119)}$

\section{Autism spectrum disorder and MNS}

It is well established that children with autism spectrum disorders (ASD) have deficits in imitation. ${ }^{120,121)}$ Because the MNS is implicated in imitation learning, recent studies have sought to examine the development of the MNS in children with ASD. In a MEG study, individuals with Asperger's syndrome showed delayed activation of the MNS in the inferior frontal lobe during an imitation task. ${ }^{122)}$ Oberman et al. ${ }^{123)}$ compared mu suppression in high-functioning individuals with ASD and age- and gender-matched control subjects while watching videos of a moving hand, a bouncing ball, and virtual noise, and while moving their own hand. Control subjects showed significant mu suppression in both, self and observed hand movements, whereas the ASD group showed significant mu suppression only in self-performed hand movements, but not in observed hand movements.

In a follow-up study, Oberman et al. ${ }^{124)}$ on mu suppression in high-functioning children with ASD and ageand gender-matched control subjects, mu suppression was measured while the ASD children watched videos of a stranger opening and closing their right hand, watched their guardian or sibling performing the same hand motion, watched their own hand performing the same action, and watched a video of two bouncing balls moving vertically toward and away from each other. The results revealed that children with ASD and typically developing children showed greater mu suppression for actions performed by familiar individuals (such as their guardians/parents) compared to those of strangers. These data showed a lack of mu suppression in the autistic children during observation, implying a possible dysfunction in the MNS. This was later developed into the "broken mirror" hypothesis.

Dapretto et al.'s fMRI study ${ }^{117)}$ specifically investigated the neural correlates of the capacity of imitating facial expressions of basic emotions in high-functioning ASD individuals. Their results showed that during observation and imitation, autistic individuals did not show activation of the MNS in the IFGpo. Importantly, activity in this area was inversely related with symptom severity in the social domain. The authors concluded that "a dysfunctional MNS may underlie the social deficits observed in autism."125)

\section{Other mental disorders and MNS}

Limited studies have examined the association between other mental disorders and problems in the MNS. They suggest that schizophrenia and psychopathy may be related to a dysfunction in the MNS. According to McCormick et al., ${ }^{126)}$ participants with active schizophrenia-spectrum and psychotic disorders showed significantly greater mu suppression in the sensorimotor cortex of the left hemisphere than they did in their residual phase and when compared to healthy individuals. Those in the residual phase and healthy individuals showed similar levels of mu suppression. That is, greater left-sided mu suppression was positively correlated with psychotic symptoms, suggesting that abnormal mirror neuron activity may exist among patients with schizophrenia during the active phase of the illness.

Negative symptoms of schizophrenia include anhedonia, affective flattening and impaired socio-emotional processing. ${ }^{127-131)}$ Empirical research has argued an association between negative symptoms and anomalous MNS activity. ${ }^{80,132-134)}$ Using fMRI, Derntl et al. ${ }^{135)}$ identified emphatic deficit in schizophrenia patients. They reported decreased brain activities in schizophrenia patients compared to healthy participants during three tasks related to empathy. Specific brain regions included those related to the MNS, such as IFG and MTG, and those associated to social cognition and emotion, such as the precuneus, cingulate, and amygdala. Using diffusion tensor imaging (DTI), Clark et al. ${ }^{136)}$ have revealed abnormality in the temporal part of the superior longitudinal fasciculus (tSLF) in patients with schizophrenia. Considering that the SLF connects the frontal, parietal, temporal, and occipital lobes and it terminates the SMA, PMv and IFG in the frontal lobe, their results suggest that damages in neural tracts connected to frontal subregions of MNS might be associated with schizophrenia. Voineskos et al. ${ }^{137)}$ have discovered abnormality in neural tracts of patients with deficit schizophrenia compared to patients with non-deficit 
schizophrenia and healthy participants. Their study suggests a significant relationships between negative symptoms of schizophrenia and abnormality of MNS, namely the arcuate fasciculus (AF) which connects two key regions of MNS, the inferior frontal and temporo-parietal areas.

Mehta et al. ${ }^{138)}$ have systematically reviewed neuroimaging studies on mirror neuron activity in schizophrenia or patients with psychosis. Most of the studies included in their review reported decreased activity of MNS in the patients; only a few reported increased activity of MNS. In addition, most studies described premotor and motor cortices as the specific brain regions for mirror activity. The IFG, IPL, and posterior superior temporal sulcus (pSTS) were also identified as parts of MNS that exhibited abnormal activity in patients.

Psychopathy appears to be the inverse of autism. In psychopathy, emotional empathy was impaired with ToM and motor empathy intact; however, in autism, emotional empathy was fully functional and ToM and motor empathy showed deficits. ${ }^{19)}$ The study of psychopathy suggested that distancing should not be pushed too far. In both cases, the diseases were understood through a refiguring of the two differences in the MNS. ${ }^{139)}$

\section{CONCLUSION}

Since its incidental discovery in macaques, the definition of mirror neurons has been extended to include a huge cerebral network. The MNS is located on the top of visual dorsal stream. This system contains supplementarymotor and temporo-parietal association areas that process visual, auditory, and somatosensory information. Table 1 includes the names and main functions of each region that constitute the MNS. Table 2 lists researches that examined specific functions of the brain in relations to specific brain regions and subregions of the MNS. Table 3 presents researches on specific psychological/psychiatric disorders related with certain areas of the brain and the subregions of MNS. The MNS is considered to be related not only with motor imitation and reading intention of other agents, but also with concepts in social interaction, such as emotion, empathy, and ToM. Hence, it is speculated that the cause of psychiatric disorders such as ASD may be strongly associated with dysfunctions of the MNS.

Indeed, MNS is important in language, learning and development itself. For example, a linkage between action and perception is thought to be important in language acquisition and utilization. ${ }^{140)}$ Subtle evidences include

Table 1. List of brain areas constitute the mirror neuron system

\begin{tabular}{|c|c|c|}
\hline Area & Brodmann area & Related function \\
\hline $\begin{array}{l}\text { Supplementary motor area (SMA), secondary } \\
\text { motor cortex (M2) }\end{array}$ & BA6 & $\begin{array}{l}\text { Postural stabilization } \\
\text { Control of sequences of movements (hypothetical) }\end{array}$ \\
\hline Premotor cortex (PMC) & BA6 & $\begin{array}{l}\text { Planning movement, spatial guidance of movement, sensory } \\
\text { guidance of movement, understanding the actions of other, } \\
\text { complex movement in hand and the mouth }\end{array}$ \\
\hline Primary motor cortex (M1) & $\begin{array}{l}\text { BA4 } \\
\text { (task-relevant) }\end{array}$ & Force in a muscle \\
\hline $\begin{array}{l}\text { Pars opercularis of the inferior frontal gyrus } \\
\text { (IFG), part of Broca's area }\end{array}$ & $\begin{array}{l}\text { BA44 } \\
\text { (task-relevant) }\end{array}$ & $\begin{array}{l}\text { Language production and phonological processing, music } \\
\text { perceptionhand movementsImpulse control (risk aversion) }\end{array}$ \\
\hline Pars triangularis of the IFG, part of Broca's area & BA45 & Semantic processing \\
\hline $\begin{array}{l}\text { Area PF/PFt of the inferior parietal lobule (IPL) } \\
\text { Supramarginal gyrus (SMG) }\end{array}$ & BA40 (rostral) & Reading both as regards meaning and phonology \\
\hline $\begin{array}{l}\text { Intraparietal sulcus (IPS) of the human } \\
\text { intraparietal area } 3 \text { (hIP3) }\end{array}$ & - & $\begin{array}{l}\text { Symbolic numerical information processing visuospatial working } \\
\text { memory, interpreting the intent of others }\end{array}$ \\
\hline Primary somatosensory cortex (S1) & BA2 & Tactile perception \\
\hline $\begin{array}{l}\text { Visual area } 5 \text { (V5) in the extrastriate areas } \\
=\text { middle temporal (MT) visual area }\end{array}$ & BA19 (partial) & $\begin{array}{l}\text { Perception of motion, integration of local motion signals into global } \\
\text { percepts, guidance of some eye movements }\end{array}$ \\
\hline Fusiform face area (FFA) & BA37 (partial) & Face and body recognition \\
\hline Fusiform body area (FBA) & & Recognition for familiar stimuli \\
\hline Posterior middle temporal gyrus (pMTG) & BA21 (caudal) & $\begin{array}{l}\text { Contemplating distance, recognition of known faces accessing word } \\
\text { meaning while reading }\end{array}$ \\
\hline Insula & BA13 (anterior) & $\begin{array}{l}\text { Olfactory perception, motor control, self-awareness interpersonal } \\
\text { experience (social emotion) }\end{array}$ \\
\hline
\end{tabular}


Table 3. List of studies concerned with the mental disorders and human mirror neuron system (MNS)

\begin{tabular}{|c|c|c|c|}
\hline Study & Topics & Related brain regions & Related MNS regions \\
\hline Dapretto et al. (2006) & Autism (observation \& imitation) & $\begin{array}{l}\text { Precentral gyrus } \\
\text { ACC } \\
\text { IFGpo } \\
\text { Insula } \\
\text { Amygdala }\end{array}$ & $\begin{array}{l}\text { M1 } \\
\text { IFG } \\
\text { Insula }\end{array}$ \\
\hline Nishitani et al. $(2004)^{122)}$ & Autism (imitation) & M1 & M1 \\
\hline Oberman et al. (2005) & Autism (observation) & Sensorymotor cortex & $\begin{array}{l}\text { M1 } \\
\text { S1 }\end{array}$ \\
\hline Oberman et al. $(2008)^{124)}$ & Autism (observation) & Sensorymotor cortex & $\begin{array}{l}\text { M1 } \\
\text { S1 }\end{array}$ \\
\hline $\begin{array}{l}\text { McCormick et al. }(2012)^{126)} \\
\text { Derntl et al. }(2012)^{135)}\end{array}$ & $\begin{array}{l}\text { Schizophrenia (empathy) } \\
\text { Schizophrenia (empathy) }\end{array}$ & $\begin{array}{l}\text { Sensorymotor cortex } \\
\text { IFG } \\
\text { MFG } \\
\text { MTG } \\
\text { ACC } \\
\text { Thalamus } \\
\text { Precuneus }\end{array}$ & $\begin{array}{l}\text { M1 } \\
\text { IFG } \\
\text { pMTG }\end{array}$ \\
\hline Clark et al. $(2011)^{136)}$ & Schizophrenia & $\begin{array}{l}\text { SLF } \\
\text { ILF } \\
\text { IFO }\end{array}$ & SLF (fronto-parietal link) \\
\hline Voineskos et al. (2013) & Schizophrenia & $\begin{array}{l}\text { Right AF } \\
\text { Right ILF } \\
\text { Left UF }\end{array}$ & $\mathrm{AF}$ (fronto-temporal link) \\
\hline
\end{tabular}

M1, primary motor cortex; ACC, anterior cingulate cortex; IFG, inferior frontal gyrus; IFGpo, IFG pars opercularis; S1, primary somatosensory cortex; MFG, middle frontal gyrus; MTG, middle temporal gyrus; pMTG, posterior MTG; SLF, superior longitudinal fasciculus; ILF, inferior longitudinal fasciculus; IFO, inferior fronto-occipital fasciculus; AF, arcuate fasciculus; UF, uncinate fasciculus.

how the IFG shows strong activation when participants imitate the actions of an experimenter. ${ }^{141)}$ More direct evidences include how language acquisition by imitation of speech sounds have been supported by the acoustic mirror neurons in Broca's area. ${ }^{2,34)}$ In their study, Tettamanti et al. ${ }^{142)}$ measured motor evoked potentials (MEP) after a single pulse TMS and simultaneously presented action-related sentences and found that the premotor mirror system modulates verbal language processing.

Regardless of the empirical support, there are skeptical opinions and controversies surrounding the existence and the role of the human MNS. Hickok ${ }^{143)}$ made a critical opinion that strongly opposed motor simulation in the Broca's area. Moreover, he argued that sensory systems are essential to recognize the actions of others. Heyes ${ }^{144)}$ also has remarked that human MNS does not work as a dominant network specialized in understanding the actions of others and has hypothesized that the mirror neurons are a byproduct of associative learning. Critiques against the human MNS, have commonly mentioned that the relation between primates' mirror neurons and the human MNS is either non-parallel or undetermined. ${ }^{143-145)}$
For such reason, Hickok ${ }^{143)}$ has argued that propositions suggesting a significant relation between the human MNS and higher social cognitive functions are mostly based on assumptions with little empirical evidence. However, these critiques do not deny the existence of mirror neurons in primates, and the existence of human mirror neurons based on a single neuron recording study by Mukamel et al. ${ }^{146)}$ These opposing arguments on the human MNS are worth considering when interpreting its relations to human behaviors.

The MNS is hypothesized to be an evolutionary precursor and launching point for much of higher cognition and complex social behavior unique and fundamental to humans. ${ }^{78)}$ Plotnik et al. ${ }^{60)}$ suggested that elephants' and dolphins' mirror self-recognition could be linked to a convergent evolution related to complex sociality and cooperation. Reiss and Marino ${ }^{52)}$ also suggested different neurological substrates of mirror self-recognition for dolphins and primates, as their brain physiology have diverged about 65 million to 70 million years ago.

Research on MNS across human, primates and other non-primate animals emphasize the idea of an ancient 
Table 2. List of studies concerned with the social cognitive function and human mirror neuron system (MNS)

\begin{tabular}{|c|c|c|c|}
\hline Study & Topics & Related brain regions & Related MNS regions \\
\hline Wicker et al. $(2003)^{88)}$ & Emotion & $\begin{array}{l}\text { Amygdala } \\
\text { Anterior insula } \\
\text { IFG } \\
\text { Right ACC }\end{array}$ & $\begin{array}{l}\text { Insula } \\
\text { IFG }\end{array}$ \\
\hline Jabbi et al. $(2007)^{89)}$ & Emotion, empathy & IFO & Insula \\
\hline Carr et al. $(2003)^{92)}$ & Empathy & $\begin{array}{l}\text { Precentral sulcus } \\
\text { M1 } \\
\text { IFG } \\
\text { STS } \\
\text { Insula } \\
\text { Right amygdala }\end{array}$ & $\begin{array}{l}\text { PMC } \\
\text { M1 } \\
\text { IFG } \\
\text { STS } \\
\text { Insula }\end{array}$ \\
\hline Singer et al. $(2004)^{93)}$ & Emotion, empathy & $\begin{array}{l}\text { PFC } \\
\text { Insula } \\
\text { ACC } \\
\text { Thalamus } \\
\text { Cerebellum }\end{array}$ & Insula \\
\hline Moll et al. $(2002)^{95)}$ & Morality & $\begin{array}{l}\text { Right medial frontal gyrus } \\
\text { Right medial OFC } \\
\text { Amygdala } \\
\text { Precuneus } \\
\text { Anterior STS } \\
\text { Posterior MTG }\end{array}$ & $\begin{array}{l}\text { STS } \\
\text { MTG }\end{array}$ \\
\hline Oberman et al. $(2007)^{98)}$ & Social action & Sensorymotor cortex & $\begin{array}{l}\text { M1 } \\
\text { S1 }\end{array}$ \\
\hline Vogeley et al. $(2001)^{101)}$ & Theory-of-mind & $\begin{array}{l}\text { Right ACC } \\
\text { Right motor cortex } \\
\text { Right PMC } \\
\text { Right TPJ }\end{array}$ & $\begin{array}{l}\text { M1 } \\
\text { PMC } \\
\text { Temporoparietal area }\end{array}$ \\
\hline Baird et al. $(2011)^{102)}$ & Empathy, theory-of-mind & $\begin{array}{l}\text { Temporoparietal area } \\
\text { mPFC } \\
\text { Temporal pole }\end{array}$ & Temporoparietal area \\
\hline Cheng et al. $(2008)^{110)}$ & Empathy & Postcentral gyrus & $\mathrm{S} 1$ \\
\hline Gutsell and Inzlicht (2010) ${ }^{111)}$ & Prejudice & Left sensorymotor cortex & $\begin{array}{l}\text { M1 } \\
\text { S1 }\end{array}$ \\
\hline Christov-Moore and lacoboni (2016) ${ }^{112)}$ & Empathy, altruism & $\begin{array}{l}\text { dIPFC } \\
\text { SPL } \\
\text { Precentral gyrus } \\
\text { Amygdala }\end{array}$ & $\begin{array}{l}\text { Parietal area } \\
\text { M1 }\end{array}$ \\
\hline Lou et al. $(2004)^{116)}$ & Concept of mental self & $\begin{array}{l}\text { Left IFC } \\
\text { Left medial frontal cortex } \\
\text { IPC } \\
\text { PCC } \\
\text { Precuneus }\end{array}$ & $\begin{array}{l}\text { IFG } \\
\text { IPL }\end{array}$ \\
\hline
\end{tabular}

IFG, inferior frontal gyrus; ACC, anterior cingulate cortex; IFO, anterior insula and adjacent frontal operculum; PMC, premotor cortex; M1, primary motor cortex; STS, superior temporal sulcus; PFC, prefrontal cortex; MTG, middle temporal gyrus; OFC, orbitofrontal cortex; S1, primary somatosensory cortex; TPJ, temoprotaietal junction; mPFC, middle PFC; dIPFC, dorsolateral PFC; SPL, superior parietal lobule; IFC, inferior frontal cortex; IPL, inferior parietal lobule; IPC, inferior parietal cortex; PCC, posterior cingulate cortex.

phylogenetic origin of the mirror mechanism and propose the function of MNS in the course of evolution. ${ }^{147)}$ A more recent epigenetic perspective can provide new insights to understand the development of mirror neurons and the differences of mirror neurons between monkeys and humans. ${ }^{148)}$ The epigenetic hypothesis proposes that the development of the MNS, which functions to encode goals and understands actions, is not simply a result of associative learning or natural selection, but is influenced by complicated epigenetic regulations that underlie neuronal plasticity, satisfying neuronal, cognitive and environmental "niches." ${ }^{149)}$ For example, research by Matsunaga 
et al. ${ }^{150)}$ suggests that the demethylation of the Gadd45 gene family may be one of the major epigenetic regulation mechanisms responsible for the growth and differentiation of neurons in the parietal cortex of mice and marmosets.

Although there are a many studies on the MNS, several questions remain unanswered. First, the relationship between the MNS and DMN needs to be clarified, as they appear to share some brain areas related to cognition regarding self. Further, some research suggests that ASD is a dysfunction of the DMN. ${ }^{151)}$ Finally, the relationship between psychiatric disorders and MNS dysfunction needs in-depth understanding, requiring more robust evidence beyond functional connectivity and neural correlates.

\section{Acknowledgments}

This work was supported by the Brain Research Program through the National Research Foundation of Korea (NRF) funded by the Ministry of Science, ICT \& Future Planning (NRF-2015M3C7A1028252), and a grant from the Korea Science and Engineering Foundation (KOSEF), funded by the Korean government (NRF-2015 R1A2A2A01003564). The authors declare that there is no conflict of interest.

\section{REFERENCES}

1. Hecht EE, Parr LA. The chimpanzee mirror system and the evolution of frontoparietal circuits for action observation and social learning. In: Ferrari PF, Rizzolatti $G$, editors. New frontiers in mirror neurons research. Oxford:Oxford University Press;2015. p. 153-181.

2. Rizzolatti G, Craighero L. The mirror-neuron system. Annu Rev Neurosci 2004;27:169-192.

3. Molenberghs $\mathrm{P}$, Brander C, Mattingley JB, Cunnington R. The role of the superior temporal sulcus and the mirror neuron system in imitation. Hum Brain Mapp 2010;31:1316-1326.

4. di Pellegrino G, Fadiga L, Fogassi L, Gallese V, Rizzolatti G. Understanding motor events: a neurophysiological study. Exp Brain Res 1992;91:176-180.

5. Gallese V, Fadiga L, Fogassi L, Rizzolatti G. Action recognition in the premotor cortex. Brain 1996;119:593-609.

6. Rizzolatti G, Fadiga L, Gallese V, Fogassi L. Premotor cortex and the recognition of motor actions. Brain Res Cogn Brain Res 1996;3:131-141.

7. Murata A, Fadiga L, Fogassi L, Gallese V, Raos V, Rizzolatti G. Object representation in the ventral premotor cortex (area F5) of the monkey. J Neurophysiol 1997;78:2226-2230.

8. Raos V, Umiltá MA, Murata A, Fogassi L, Gallese V.
Functional properties of grasping-related neurons in the ventral premotor area F5 of the macaque monkey. J Neurophysiol 2006;95:709-729.

9. Orban GA. The mirror system in human and nonhuman primates: Comparative functional imaging studies suggest multiple systems. In: Ferrari PF, Rizzolatti G, editors. New frontiers in mirror neurons research. Oxford:Oxford University Press;2015. p.116-137.

10. Rizzolatti G, Luppino G. The cortical motor system. Neuron 2001;31:889-901.

11. Kraskov A, Dancause N, Quallo MM, Shepherd S, Lemon RN. Corticospinal neurons in macaque ventral premotor cortex with mirror properties: a potential mechanism for action suppression? Neuron 2009;64:922-930.

12. Vigneswaran G, Philipp R, Lemon RN, Kraskov A. M1 corticospinal mirror neurons and their role in movement suppression during action observation. Curr Biol 2013;23:236243.

13. Bahlmann J, Schubotz RI, Friederici AD. Hierarchical artificial grammar processing engages Broca's area. Neuroimage 2008:42:525-534.

14. Fazio P, Cantagallo A, Craighero L, D’Ausilio A, Roy AC, Pozzo T, et al. Encoding of human action in Broca's area. Brain 2009;132:1980-1988.

15. Rizzolatti G, Fadiga L, Fogassi L, Gallese V. From mirror neurons to imitation: facts and speculations. In: Meltzoff $A \mathrm{~N}$, Prinz W, editors. The imitative mind: development, evolution, and brain bases. Cambridge:Cambridge University Press;2002. p.247-266.

16. Bonini L, Rozzi S, Serventi FU, Simone L, Ferrari PF, Fogassi L. Ventral premotor and inferior parietal cortices make distinct contribution to action organization and intention understanding. Cereb Cortex 2010;20:1372-1385.

17. Rozzi S, Ferrari PF, Bonini L, Rizzolatti G, Fogassi L. Functional organization of inferior parietal lobule convexity in the macaque monkey: electrophysiological characterization of motor, sensory and mirror responses and their correlation with cytoarchitectonic areas. Eur I Neurosci 2008; 28:1569-1588.

18. Fogassi L, Ferrari PF, Gesierich B, Rozzi S, Chersi F, Rizzolatti G. Parietal lobe: from action organization to intention understanding. Science 2005;308:662-667.

19. Puce A, Perrett D. Electrophysiology and brain imaging of biological motion. Philos Trans $R$ Soc Lond B Biol SCi 2003;358:435-445.

20. Perrett DI, Harries MH, Bevan R, Thomas S, Benson PJ, Mistlin AJ, et al. Frameworks of analysis for the neural representation of animate objects and actions. J Exp Biol 1989; 146:87-113.

21. Allison T, Puce A, McCarthy G. Social perception from visual cues: role of the STS region. Trends Cogn Sci 2000;4:267278.

22. Pineda JA. The functional significance of mu rhythms: trans- 
lating "seeing" and "hearing" into "doing". Brain Res Brain Res $\operatorname{Rev} 2005 ; 50: 57-68$

23. Fabbri-Destro M, Rizzolatti G. Mirror neurons and mirror systems in monkeys and humans. Physiology (Bethesda) 2008;23:171-179.

24. Borra E, Belmalih A, Calzavara R, Gerbella M, Murata A, Rozzi S, et al. Cortical connections of the macaque anterior intraparietal (AIP) area. Cereb Cortex 2008;18:1094-1111.

25. Pineda JA. Sensorimotor cortex as a critical component of an 'extended' mirror neuron system: Does it solve the development, correspondence, and control problems in mirroring? Behav Brain Funct 2008:4:47.

26. Rozzi S. The neuroanatomy of the mirror neuron system. In: Ferrari PF, Rizzolatti $G$, editors. New frontiers in mirror neurons research. Oxford:Oxford University Press;2015. p.3-22.

27. Uddin LQ, lacoboni M, Lange C, Keenan JP. The self and social cognition: the role of cortical midline structures and mirror neurons. Trends Cogn Sci 2007;11:153-157.

28. Caspers S, Zilles K, Laird AR, Eickhoff SB. ALE meta-analysis of action observation and imitation in the human brain. Neuroimage 2010;50:1148-1167.

29. Gerbella M, Belmalih A, Borra E, Rozzi S, Luppino G. Cortical connections of the macaque caudal ventrolateral prefrontal areas 45A and 45B. Cereb Cortex 2010;20:141168.

30. Hadjikhani N, Joseph RM, Snyder J, Tager-Flusberg H. Abnormal activation of the social brain during face perception in autism. Hum Brain Mapp 2007;28:441-449.

31. Montgomery KJ, Haxby JV. Mirror neuron system differentially activated by facial expressions and social hand gestures: a functional magnetic resonance imaging study. J Cogn Neurosci 2008;20:1866-1877.

32. Rizzolatti G, Camarda R, Fogassi L, Gentilucci M, Luppino G, Matelli M. Functional organization of inferior area 6 in the macaque monkey. II. Area F5 and the control of distal movements. Exp Brain Res 1988;71:491-507.

33. Umiltà MA, Kohler E, Gallese V, Fogassi L, Fadiga L, Keysers C, et al. I know what you are doing. A neurophysiological study. Neuron 2001;31:155-165.

34. Kohler E, Keysers C, Umiltà MA, Fogassi L, Gallese V, Rizzolatti G. Hearing sounds, understanding actions: action representation in mirror neurons. Science 2002;297:846848.

35. Frith CD, Frith U. Social cognition in humans. Curr Biol 2007;17:R724-R732.

36. Ishida H, Nakajima K, Inase M, Murata A. Shared mapping of own and others' bodies in visuotactile bimodal area of monkey parietal cortex. J Cogn Neurosci 2010;22:83-96.

37. Caggiano V, Fogassi L, Rizzolatti G, Thier P, Casile A. Mirror neurons differentially encode the peripersonal and extrapersonal space of monkeys. Science 2009;324:403-406.

38. Caggiano V, Fogassi L, Rizzolatti G, Pomper JK, Thier P, Giese MA, et al. View-based encoding of actions in mirror neurons of area f5 in macaque premotor cortex. Curr Biol 2011;21:144-148.

39. Ferrari PF, Paukner A, Ruggiero A, Darcey L, Unbehagen S, Suomi SJ. Interindividual differences in neonatal imitation and the development of action chains in rhesus macaques. Child Dev 2009;80:1057-1068.

40. Nottebohm F. The neural basis of birdsong. PLoS Biol 2005; 3:e164.

41. Mooney R. Auditory-vocal mirroring in songbirds. Philos Trans R Soc Lond B Biol Sci 2014;369:20130179.

42. Reiner A, Perkel DJ, Mello CV, Jarvis ED. Songbirds and the revised avian brain nomenclature. Ann $N Y$ Acad Sci 2004; 1016:77-108.

43. Mooney R. Neurobiology of song learning. Curr Opin Neurobiol 2009; 19:654-660.

44. Nottebohm F, Stokes TM, Leonard CM. Central control of song in the canary, Serinus canarius. J Comp Neurol 1976; 165:457-486.

45. Prather JF, Mooney R. Mirror neurons in the songbird brain: a neural interface for learned vocal communication. In: Ferrari $P F$, Rizzolatti $G$, editors. New frontiers in mirror neurons research. Oxford:Oxford University Press;2015. p.182-197.

46. Vates GE, Vicario DS, Nottebohm F. Reafferent thalamo"cortical" loops in the song system of oscine songbirds. J Comp Neurol 1997;380:275-290.

47. Bottjer SW, Johnson F. Circuits, hormones, and learning: vocal behavior in songbirds. J Neurobiol 1997;33:602-618.

48. Luo M, Perkel DJ. A GABAergic, strongly inhibitory projection to a thalamic nucleus in the zebra finch song system. J Neurosci 1999;19:6700-6711.

49. Aronov D, Andalman AS, Fee MS. A specialized forebrain circuit for vocal babbling in the juvenile songbird. Science 2008;320:630-634.

50. Brenowitz EA. Altered perception of species-specific song by female birds after lesions of a forebrain nucleus. Science 1991;251:303-305.

51. Gentner TQ, Hulse SH, Bentley GE, Ball GF. Individual vocal recognition and the effect of partial lesions to HVC on discrimination, learning, and categorization of conspecific song in adult songbirds. J Neurobiol 2000;42:117-133.

52. Reiss D, Marino L. Mirror self-recognition in the bottlenose dolphin: a case of cognitive convergence. Proc Natl Acad SCi U S A 2001;98:5937-5942.

53. Herman LM, Matus DS, Herman EYK, Ivancic M, Pack AA. The bottlenosed dolphin's (Tursiops truncatus) understanding of gestures as symbolic representations of its body parts. Anim Learn Behav 2001;29:250-264.

54. Marten K, Psarakos S. Evidence for self-awareness in the bottlenose dolphin (Tursiops truncates). In: Parker ST, Mitchell $R W$, Boccia ML, editors. Self-awareness in animals and humans: developmental perspectives. Cambridge:Cambridge University Press; 1994. p.361-379.

55. Herman LM, Morrel-Samuels P, Pack AA. Bottlenosed do/- 
phin and human recognition of veridical and degraded video displays of an artificial gestural language. J Exp Psychol Gen 1990;119:215-230.

56. Jeannerod $M$. The mechanism of self-recognition in humans. Behav Brain Res 2003;142:1-15.

57. Allman JM, Watson KK, Tetreault NA, Hakeem AY. Intuition and autism: a possible role for Von Economo neurons. Trends Cogn Sci 2005;9:367-373.

58. Hakeem AY, Sherwood CC, Bonar CJ, Butti C, Hof PR, Allman JM. Von Economo neurons in the elephant brain. Anat Rec (Hoboken) 2009;292:242-248.

59. Butti C, Sherwood CC, Hakeem AY, Allman JM, Hof PR. Total number and volume of Von Economo neurons in the cerebral cortex of cetaceans. J Comp Neurol 2009;515:243-259.

60. Plotnik JM, de Waal FB, Reiss D. Self-recognition in an Asian elephant. Proc Natl Acad Sci U S A 2006; 103:17053-17057.

61. Marshall PJ, Bar-Haim Y, Fox NA. Development of the EEG from 5 months to 4 years of age. Clin Neurophysiol 2002; 113:1199-1208.

62. Muthukumaraswamy SD, Johnson BW, McNair NA. Mu rhythm modulation during observation of an object-directed grasp. Brain Res Cogn Brain Res 2004;19:195-201.

63. Saby JN, Marshall PJ, Meltzoff AN. Neural correlates of being imitated: an EEG study in preverbal infants. Soc Neurosci 2012;7:650-661.

64. Nyström P. The infant mirror neuron system studied with high density EEG. SOC Neurosci 2008;3:334-347.

65. Hari R, Forss N, Avikainen S, Kirveskari E, Salenius S, Rizzolatti G. Activation of human primary motor cortex during action observation: a neuromagnetic study. Proc Natl Acad Sci U S A 1998;95:15061-15065.

66. Arnstein D, Cui F, Keysers C, Maurits NM, Gazzola V. $\mu$-suppression during action observation and execution correlates with BOLD in dorsal premotor, inferior parietal, and $S I$ cortices. J Neurosci 2011;31:14243-14249.

67. Braadbaart L, Williams JH, Waiter GD. Do mirror neuron areas mediate mu rhythm suppression during imitation and action observation? Int J Psychophysiol 2013;89:99-105.

68. Mizuhara H. Cortical dynamics of human scalp EEG origins in a visually guided motor execution. Neuroimage 2012;62: 1884-1895.

69. Perry A, Bentin S. Mirror activity in the human brain while observing hand movements: a comparison between EEG desynchronization in the mu-range and previous $\mathrm{AMRI}$ results. Brain Res 2009;1282:126-132.

70. Aleksandrov AA, Tugin SM. Changes in the Mu rhythm in different types of motor activity and on observation of movements. Neurosci Behav Physiol 2012;42:302-307.

71. Perry A, Bentin S. Does focusing on hand-grasping intentions modulate electroencephalogram $\mu$ and a suppressions? Neuroreport 2010;21:1050-1054.

72. Muthukumaraswamy SD, Singh KD. Modulation of the human mirror neuron system during cognitive activity.
Psychophysiology 2008;45:896-905.

73. Rossi S, Tecchio F, Pasqualetti P, Ulivelli M, Pizzella V, Romani GL, et al. Somatosensory processing during movement observation in humans. Clin Neurophysiol 2002;113: 16-24.

74. Hobson HM, Bishop DVM. Mu suppression - A good measure of the human mirror neuron system? Cortex 2016;82:290310.

75. Hari R, Salmelin R. Human cortical oscillations: a neuromagnetic view through the skull. Trends Neurosci 1997;20: 44-49.

76. Ritter P, Moosmann M, Villringer A. Rolandic alpha and beta EEG rhythms' strengths are inversely related to fMRI-BOLD signal in primary somatosensory and motor cortex. Hum Brain Mapp 2009;30:1168-1187.

77. Frenkel-Toledo S, Bentin S, Perry A, Liebermann DG, Soroker N. Dynamics of the EEG power in the frequency and spatial domains during observation and execution of manual movements. Brain Res 2013;1509:43-57.

78. Yoo KH, Fox NA. The mirror neuron system and the mu rhythm. In: Ferrari PF, Rizzolatti $G$, editors. New frontiers in mirror neurons research. Oxford:Oxford University Press; 2015. p.256-273.

79. Heiser M, lacoboni M, Maeda F, Marcus J, Mazziotta JC. The essential role of Broca's area in imitation. Eur I Neurosci 2003; 17:1123-1128.

80. lacoboni M, Woods RP, Brass M, Bekkering H, Mazziotta JC, Rizzolatti G. Cortical mechanisms of human imitation. Science 1999;286:2526-2528.

81. Buccino G, Binkofski F, Fink GR, Fadiga L, Fogassi L, Gallese $\mathrm{V}$, et al. Action observation activates premotor and parietal areas in a somatotopic manner: an fMRI study. Eur J NeurosCi 2001;13:400-404.

82. Lui F, Buccino G, Duzzi D, Benuzzi F, Crisi G, Baraldi P, et al. Neural substrates for observing and imagining non-object-directed actions. Soc Neurosci 2008;3:261-275.

83. Saygin AP, Wilson SM, Hagler DJ Jr, Bates E, Sereno MI. Point-light biological motion perception activates human premotor cortex. J Neurosci 2004;24:6181-6188.

84. Tai YF, Scherfler C, Brooks DJ, Sawamoto N, Castiello U. The human premotor cortex is 'mirror' only for biological actions. Curr Biol 2004; 14:117-120.

85. Gazzola V, Aziz-Zadeh L, Keysers C. Empathy and the somatotopic auditory mirror system in humans. Curr Biol 2006; 16:1824-1829.

86. Engel A, Burke M, Fiehler K, Bien S, Rosler F. How moving objects become animated: the human mirror neuron system assimilates non-biological movement patterns. Soc Neurosci 2008;3:368-387.

87. Molenberghs P, Cunnington R, Mattingley JB. Brain regions with mirror properties: a meta-analysis of 125 human $\mathrm{fMRI}$ studies. Neurosci Biobehav Rev 2012;36:341-349.

88. Wicker B, Keysers C, Plailly J, Royet JP, Gallese V, Rizzolatti 
G. Both of us disgusted in My insula: the common neural basis of seeing and feeling disgust. Neuron 2003;40:655-664.

89. Jabbi M, Swart M, Keysers C. Empathy for positive and negative emotions in the gustatory cortex. Neuroimage 2007; 34:1744-1753.

90. de Vignemont F, Singer T. The empathic brain: how, when and why? Trends Cogn Sci 2006;10:435-441.

91. Gallese V, Keysers C, Rizzolatti G. A unifying view of the basis of social cognition. Trends Cogn Sci 2004;8:396-403.

92. Carr L, lacoboni M, Dubeau MC, Mazziotta JC, Lenzi GL. Neural mechanisms of empathy in humans: a relay from neural systems for imitation to limbic areas. Proc Natl Acad SciU S A 2003; 100:5497-5502.

93. Singer T, Seymour B, O’Doherty J, Kaube H, Dolan RJ, Frith $\mathrm{CD}$. Empathy for pain involves the affective but not sensory components of pain. Science 2004;303:1157-1162.

94. Molnar-Szakacs I. From actions to empathy and morality- $A$ neural perspective. J Econ Behav Organ 2011;77:76-85.

95. Moll J, de Oliveira-Souza R, Eslinger PJ, Bramati IE, MourãoMiranda J, Andreiuolo PA, et al. The neural correlates of moral sensitivity: a functional magnetic resonance imaging investigation of basic and moral emotions. I Neurosci 2002; 22:2730-2736.

96. Woodward AL, Gerson SA. Mirroring and the development of action understanding. Philos Trans $R$ Soc Lond B Biol SCi 2014;369:20130181.

97. Schulte-Rüther M, Markowitsch HJ, Fink GR, Piefke M. Mirror neuron and theory of mind mechanisms involved in face-to-face interactions: a functional magnetic resonance imaging approach to empathy. J Cogn Neurosci 2007;19: 1354-1372.

98. Oberman LM, Pineda JA, Ramachandran VS. The human mirror neuron system: a link between action observation and social skills. Soc Cogn Affect Neurosci 2007;2:62-66.

99. Rizzolatti G, Fogassi L, Gallese V. Neurophysiological mechanisms underlying the understanding and imitation of action. Nat Rev Neurosci 2001;2:661-670.

100. Vogeley K, Fink GR. Neural correlates of the first-person-perspective. Trends Cogn Sci 2003;7:38-42.

101. Vogeley K, Bussfeld P, Newen A, Herrmann S, Happé F, Falkai $\mathrm{P}$, et al. Mind reading: neural mechanisms of theory of mind and self-perspective. Neuroimage 2001;14:170-181.

102. Baird AD, Scheffer IE, Wilson SJ. Mirror neuron system involvement in empathy: a critical look at the evidence. Soc Neurosci 2011;6:327-335.

103. Gallese V. The 'shared manifold' hypothesis. From mirror neurons to empathy. I Conscious Stud 2001;8:33-50.

104. Gallese V. The roots of empathy: the shared manifold hypothesis and the neural basis of intersubjectivity. Psychopathology 2003;36:171-180.

105. Rizzolatti G, Craighero L. Mirror neuron: a neurological approach to empathy. In: Changeux JP, Damasio AR, Singer W, Christen $Y$, editors. Neurobiology of human values. Berlin:
Springer-Verlag Berlin Heidelberg;2005. p.107-123.

106. Phillips ML, Young AW, Senior C, Brammer M, Andrew C, Calder AJ, et al. A specific neural substrate for perceiving facial expressions of disgust. Nature 1997;389:495-498.

107. Calder AJ, Keane J, Manes F, Antoun N, Young AW. Impaired recognition and experience of disgust following brain injury. Nat Neurosci 2000;3:1077-1078.

108. Adolphs R, Tranel D, Damasio AR. Dissociable neural systems for recognizing emotions. Brain Cogn 2003;52:61-69.

109. Goldman Al, Sripada CS. Simulationist models of face-based emotion recognition. Cognition 2005;94:193-213.

110. Cheng Y, Yang CY, Lin CP, Lee PL, Decety J. The perception of pain in others suppresses somatosensory oscillations: a magnetoencephalography study. Neuroimage 2008:40: 1833-1840.

111. Gutsell JN, Inzlicht M. Empathy constrained: Prejudice predicts reduced mental simulation of actions during observation of outgroups. J Exp Soc Psychol 2010;46:841-845.

112. Christov-Moore L, lacoboni M. Self-other resonance, its control and prosocial inclinations: Brain-behavior relationships. Hum Brain Mapp 2016;37:1544-1558.

113. Northoff G, Bermpohl F. Cortical midline structures and the self. Trends Cogn Sci 2004;8:102-107.

114. Schilbach L, Wohlschlaeger AM, Kraemer NC, Newen A, Shah NJ, Fink GR, et al. Being with virtual others: Neural correlates of social interaction. Neuropsychologia 2006;44: 718-730.

115. Goldman Al. Mirroring, simulating and mindreading. Mind Lang 2009;24:235-252.

116. Lou HC, Luber B, Crupain M, Keenan JP, Nowak M, Kjaer TW, et al. Parietal cortex and representation of the mental Self. Proc Natl Acad Sci U S A 2004;101:6827-6832.

117. Dapretto M, Davies MS, Pfeifer JH, Scott AA, Sigman M, Bookheimer SY, et al. Understanding emotions in others: mirror neuron dysfunction in children with autism spectrum disorders. Nat Neurosci 2006;9:28-30.

118. Enticott PG, Hoy KE, Herring SE, Johnston PJ, Daskalakis ZJ, Fitzgerald PB. Reduced motor facilitation during action observation in schizophrenia: a mirror neuron deficit? Schizophr Res 2008;102:116-121.

119. Fecteau S, Pascual-Leone A, Théoret H. Psychopathy and the mirror neuron system: preliminary findings from a non-psychiatric sample. Psychiatry Res 2008;160:137-144.

120. Williams JH, Whiten A, Singh T. A systematic review of action imitation in autistic spectrum disorder. J Autism Dev Disord 2004;34:285-299.

121. Oh DH, Kim IB, Kim SH, Ahn DH. Predicting autism spectrum disorder using blood-based gene expression signatures and machine learning. Clin Psychopharmacol Neurosci 2017; 15:47-52.

122. Nishitani N, Avikainen S, Hari R. Abnormal imitation-related cortical activation sequences in Asperger's syndrome. Ann Neurol 2004;55:558-562. 
123. Oberman LM, Hubbard EM, McCleery JP, Altschuler EL, Ramachandran VS, Pineda JA. EEG evidence for mirror neuron dysfunction in autism spectrum disorders. Brain Res Cogn Brain Res 2005;24:190-198.

124. Oberman LM, Ramachandran VS, Pineda JA. Modulation of mu suppression in children with autism spectrum disorders in response to familiar or unfamiliar stimuli: the mirror neuron hypothesis. Neuropsychologia 2008;46:1558-1565.

125. Gallese V. Intentional attunement: a neurophysiological perspective on social cognition and its disruption in autism. Brain Res 2006;1079:15-24.

126. McCormick LM, Brumm MC, Beadle JN, Paradiso S, Yamada T, Andreasen N. Mirror neuron function, psychosis, and empathy in schizophrenia. Psychiatry Res 2012;201:233-239.

127. Kirkpatrick B, Buchanan RW, Ross DE, Carpenter WT Jr. $A$ separate disease within the syndrome of schizophrenia. Arch Gen Psychiatry 2001;58:165-171.

128. Lee KH, Farrow TF, Spence SA, Woodruff PW. Social cognition, brain networks and schizophrenia. Psychol Med 2004; 34:391-400.

129. Mölle M, Marshall L, Fehm HL, Born J. EEG theta synchronization conjoined with alpha desynchronization indicate intentional encoding. Eur J Neurosci 2002;15:923-928.

130. Kim SJ, Shim JC, Kong BG, Kang JW, Moon JJ, Jeon DW, et al. The relationship between language ability and cognitive function in patients with schizophrenia. Clin Psychopharmacol Neurosci 2015;13:288-295.

131. Kim SW, Lee JY, Kang HJ, Kim SY, Bae KY, Kim JM, et al. Gender-specific associations of the brain-derived neurotrophic factor Val66met polymorphism with neurocognitive and clinical features in schizophrenia. Clin Psychopharmacol Neurosci 2016;14:270-278.

132. lacoboni M. Neural mechanisms of imitation. Curr Opin Neurobiol 2005;15:632-637.

133. lacoboni M, Molnar-Szakacs I, Gallese V, Buccino G, Mazziotta JC, Rizzolatti G. Grasping the intentions of others with one's own mirror neuron system. PLoS Biol 2005; 3:e79.

134. Gur RE, Kohler CG, Ragland JD, Siegel SJ, Lesko K, Bilker WB, et al. Flat affect in schizophrenia: relation to emotion processing and neurocognitive measures. Schizophr Bull 2006;32: 279-287.

135. Derntl B, Finkelmeyer A, Voss B, Eickhoff SB, Kellermann T, Schneider F, et al. Neural correlates of the core facets of empathy in schizophrenia. Schizophr Res 2012;136:70-81.

136. Clark KA, Nuechterlein KH, Asarnow RF, Hamilton LS, Phillips OR, Hageman NS, et al. Mean diffusivity and fractional anisotropy as indicators of disease and genetic liability to schizophrenia. J Psychiatr Res 2011;45:980-988.

137. Voineskos AN, Foussias G, Lerch J, Felsky D, Remington G, Rajji TK, et al. Neuroimaging evidence for the deficit subtype of schizophrenia. JAMA Psychiatry 2013;70:472-480.
138. Mehta UM, Thirthalli J, Aneelraj D, Jadhav P, Gangadhar BN, Keshavan MS. Mirror neuron dysfunction in schizophrenia and its functional implications: a systematic review. Schizophr Res 2014;160:9-19.

139. Guenther K. Imperfect reflections: norms, pathology, and difference in mirror neuron research. In: Bates D, Bassiri $N$, editors. Plasticity and pathology: on the formation of the neural subject. New York:Fordham University Press;2016. p.268-308.

140. Nishitani N, Schürmann M, Amunts K, Hari R. Broca's region: from action to language. Physiology (Bethesda) 2005; 20:60-69.

141. Grafton ST, Arbib MA, Fadiga L, Rizzolatti G. Localization of grasp representations in humans by positron emission tomography. 2. Observation compared with imagination. Exp Brain Res 1996;112:103-111.

142. Tettamanti M, Buccino G, Saccuman MC, Gallese V, Danna $\mathrm{M}$, Scifo $\mathrm{P}$, et al. Listening to action-related sentences activates fronto-parietal motor circuits. J Cogn Neurosci 2005; 17:273-281.

143. Hickok G. Eight problems for the mirror neuron theory of action understanding in monkeys and humans. J Cogn Neurosci 2009;21:1229-1243.

144. Heyes C. Where do mirror neurons come from? NeurosCi Biobehav Rev 2010;34:575-583.

145. Dinstein I, Thomas C, Behrmann M, Heeger DJ. A mirror up to nature. Curr Biol 2008;18:R13-R18.

146. Mukamel R, Ekstrom AD, Kaplan J, lacoboni M, Fried I. Single-neuron responses in humans during execution and observation of actions. Curr Biol 2010;20:750-756.

147. Bonini L, Ferrari PF. Evolution of mirror systems: a simple mechanism for complex cognitive functions. Ann N Y Acad Sci 2011;1225:166-175.

148. Ferrari PF, Tramacere A, Simpson EA, Iriki A. Mirror neurons through the lens of epigenetics. Trends Cogn Sci 2013;17: 450-457.

149. Tramacere A, Ferrari PF, Iriki A. Epigenetic regulation of mirror neuron development, and related evolutionary hypotheses. In: Ferrari PF, Rizzolatti G, editors. New frontiers in mirror neurons research. Oxford:Oxford University Press;2015. p.222-244.

150. Matsunaga E, Nambu S, Oka M, Iriki A. Comparative analysis of developmentally regulated expressions of Gadd45a, Gadd45b, and Gadd45g in the mouse and marmoset cerebral cortex. Neuroscience 2015;284:566-580.

151. Yerys BE, Gordon EM, Abrams DN, Satterthwaite TD, Weinblatt R, Jankowski KF, et al. Default mode network segregation and social deficits in autism spectrum disorder: Evidence from non-medicated children. Neuroimage Clin 2015;9:223-232. 